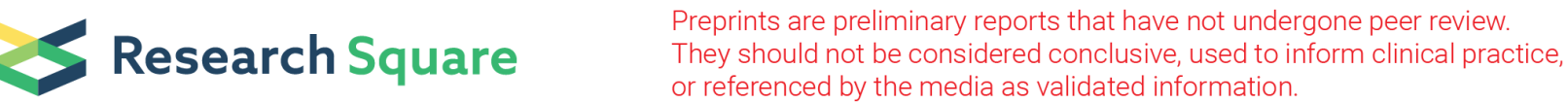

\section{PD-L1 and JAK2 mRNA level in essential thrombocythaemia depends on the driver mutational status and the bone marrow fibrosis grade}

Krzysztof Lewandowski ( $\sim$ lewandowski@ump.edu.pl )

Poznan University of Medical Sciences

Zuzanna Kanduła

Poznan University of Medical Sciences

Michał Gniot

Poznan University of Medical Sciences

Edyta Paczkowska

Pomeranian Medical University

Paulina Maria Nawrocka

Polish Academy of Sciences

Marzena Wojtaszewska

Poznan University of Medical Sciences

Michał Janowski

Pomeranian Medical University

Magdalena Mariak

Poznan University of Medical Sciences

Luiza Handschuh

Poznan University of Technology

Piotr Kozlowski

Polish Academy of Sciences

\section{Research Article}

Keywords: essential thrombocythaemia, post-essential thrombocythaemia myelofibrosis, JAK2V617F allele burden, JAK2V617F expression, total JAK2 expression, PDL1 expression, driver defects, non-driver defects

Posted Date: February 17th, 2022

DOI: https://doi.org/10.21203/rs.3.rs-1347762/v1 
License: (c) (i) This work is licensed under a Creative Commons Attribution 4.0 International License. Read Full License 


\section{Abstract}

Background: JAK-STAT pathway activation leads to an enhanced activity of the promoter of CD274 (PDL1) coding programmed death-1 receptor ligand (PD-L1), increased PD-L1 level and the immune escape of myeloproliferative neoplasms (MPN) cells. It has been postulated that the bone marrow failure, bone marrow myeloid metaplasia, and changes in the molecular characteristics of the malignant clone(s) during MPN outcome may influence the JAK2 and PDL 1 gene expression.

Aim: to evaluate the PDL 1 mRNA and JAK2 mRNA level in molecularly defined essential thrombocythaemia (ET) patients (pts) during disease progression to post-ET- myelofibrosis (post-ET-MF).

Methods: the study group consisted of 162 ET pts, including 30 diagnosed with post-ET-MF.

Results: the JAK2V617F, CALR, and MPL mutations were found in $59.3 \%, 19.1 \%$, and $1.2 \%$ of pts, respectively. The total JAK2 mRNA level (V617F+WT) did not differ according to the JAK2 haplotype ${ }^{\mathrm{GGCC}-46 / 1}$ or the type of driver defect. No copy-number alternations of the JAK2, PDL 1, and $P D C D L 1 G 2$ (PDL2) genes were found. The level of PD-L1 was significantly higher in the JAK2V617F than in the JAK2WT, CALR mutation-positive, and triple-negative pts. The PD-L1 mRNA level was weakly correlated with both the JAK2V617F variant allele frequency (VAF), and with the JAK2V617F allele mRNA level. The total JAK2 level in post-ET-MF pts was lower than in ET pts despite the lack of differences in the JAK2V617F VAF. In addition, the PD-L1 level was lower in post-ET-MF. The detailed analysis has shown that the decrease in JAK2 and PD-L1 mRNA levels depended on the bone marrow fibrosis grade. The PDL 1 expression showed no difference in relation to the genotype of $46 / 1$ haplotype, hemoglobin concentration, hematocrit value, leukocyte, and platelet counts.

Conclusion: the study confirmed the correlation between the PD-L1 and JAK2 mRNA level in ET pts. The observed drop of the total JAK2 and PD-L1 levels during the ET progression to the post-ET-MF may reflect the changes in the JAK2V617F positive clone proliferative potential and the PD-L1 level related immunosuppressive effect. This decrease could explain the lack of efficacy of the pembrolizumab in patients with advanced post-ET-MF and post-polycythemia vera myelofibrosis which was recently reported.

\section{Introduction}

Activation of the Janus kinase - a signal transducer and activator of transcription (JAK-STAT) signaling pathway in myeloid progenitor cells, is a hallmark of Philadelphia negative myeloid neoplasms (MPNPh-). It resulted in the proliferative advantage of myeloid cells, leading to clinical and laboratory symptoms of MPN $(1,2)$. In the majority of MPNPh- patients (pts), clonal proliferation of myeloid progenitor cells is the result of the mutation acquisition by hematopoietic stem cells in the gene coding proteins of the JAKSTAT signaling pathway (3). In 2005, a gain-of-function point mutation in Janus 2 kinase gene (JAK2) was discovered and characterized by a few independent scientific groups (4-6). The presence of another somatic activating mutation of the thrombopoietin receptor gene (MPL proto-oncogene) was confirmed 
by Pikman et al. and, independently, by Pardanani et al. in $2006(7,8)$. The most frequent mutations affect the hotspot codon W515 (W515L/R/A/G) which is localized at the boundary of the transmembrane and the cytosolic domains of MPL (9). W515 prevents spontaneous activation of MPL, but in the case of gain-off-function MPL mutations, the TPO-independent activation of the receptor takes place, resulting in the downstream JAK-STAT pathway signaling (10). In 2013, the whole-exome sequencing studies confirmed the presence of recurrent frameshift mutation in the calreticulin gene (CALR) in ET pts negative for JAK2 and MPL mutation $(11,12)$. Until now, more than 60 mutations in CALR in MPN pts have been identified. Eighty percent of them are type 1 (a 52bp deletion; c.1099_1150del, p.Leu367Thrfs*46) or type 2 mutations (a 5bp insertion; c.1154_1155insTTGTC, p.Lys385Asnfs*47). The rest of the CALR gene mutations can be categorized into type-1-like, type-2-like, or other types (13). According to recent data, the distribution of CALR mutations varies dependently from the type of MPNPh-. In ET, the distribution of type 1 and type 2 mutations is similar (51 vs. $39 \%$ of pts, respectively) $(14,15)$. The CALR mutants form a molecular complex with thrombopoietin receptor, determining a cytokine-independent JAK-STAT activation with an increased megakaryocyte proliferation $(16,17)$. Recently, it has been postulated that defective interactions of mutant CALR with store-operated calcium (Ca2+) entry machinery (SOCE) are responsible for (i) constitutive activation of SOCE, (ii) MPL activation, and (iii) subsequent phosphorylation of STAT5, AKT, and ERK1/2 and (iv) megakaryocyte proliferation (15). In the case of the MPL gene mutations, coding the thrombopoietin receptor structure, the constitutive activation of thrombopoietin receptor activation is responsible for JAK-STAT pathway activation (9).

The proliferation and differentiation of MPNPh- cells due to abnormal JAK-STAT pathway signaling results in an indirect paracrine secretion of inflammatory cytokines released by the bone marrow microenvironment cells and the cytokine storm. One of the consequences is bone marrow fibrosis associated with an increased level of interleukin 8 (IL-8), oncostatin-M, lipocalin-2, transforming growth factor $\beta 1$, platelet derived growth factor (PDGF), fibroblast growth factor (FGF), venous endothelial growth factor (VEGF), and inhibitors of matrix metalloproteinases in the peripheral blood (18-20). The frequency of fibrotic transformation of ET to post-essential thrombocythaemia myelofibrosis (post-ETMF) was determined as $0.8-4.9 \%$ at 10 and $4-11 \%$ at 15 years, respectively (21). According to the available data, the cumulative risk of post-ET-MF increases over time and is $0.3 \%$ at 5 years and $3.9 \%$ at 10 years, with the median follow-up time of 9.1 years (22). Pre-fibrotic primary myelofibrosis bone marrow morphology, advanced age, and anemia were identified as factors predisposing to post-ET-MF. The presence of the JAK2 mutation was associated with a low fibrotic transformation risk of ET (23-25). It has been also postulated that JAK2V617F variant allele frequency (VAF) is correlated with fibrotic progression (26).

Hao et al. and, independently, Barrett et al. postulated a possible relation between the expression of JAK2, and the PD-1 ligand genes ( $P D-L 1$ and $P D-L 2)$, because all of them are located on chromosome 9p24.1, and an amplification of chromosome 9p24.1 upregulated the JAK2 expression and activated the JAK2STAT3 pathway $(27,28)$. It was found that JAK2V617F oncogenic activity resulted in an increased phosphorylation of STAT3 and STAT5 and enhanced PD-L1 promotor activity and PD-L1 protein level (29). The up-regulation of PD-L1 resulted in a reduced cytotoxic T-cell activity, cell cycle progression, and 
T cell exhaustion (30)(31). Recently, Milosevic-Feenstra et al. documented a higher PD-L1 mRNA expression in granulocytes in both JAK2V617F positive ET and primary myelofibrosis (PMF) patients, compared to CALR-mutated MPN patients. Moreover, they showed that MPN cells in JAK2-V617F-positive patients expressed higher levels of PD-L1, if 9p uniparental disomy (UPD) was present (32). The aforementioned mechanism may confer a potent escape mechanism of MPN cells from the host immune system and disease progression. Therefore, our study aimed to evaluate the PD-L1 and JAK2 mRNA expression in molecularly defined ET patients, dependently from the disease phase, to answer the question of the mutual relation between the PD-L1mRNA and JAK2 mRNA expression and disease progression to post-ET-MF.

\section{Materials And Methods}

Study group characteristics

The study group consisted of 132 pts with ET and 30 persons with a confirmed diagnosis of post-ET-MF according to the WHO criteria published in 2016 (33). The pts were recruited from two academic centers - the Department of Hematology and Bone Marrow Transplantation of Poznan University of Medical Sciences in Poznan, Poland, and the Department of Hematology and Department of General Pathology of Pomeranian Medical University in Szczecin, Poland. A detailed characteristics of the pts is presented in Table 1. The clinical patient workup included physical examination, ultrasonography, magnetic resonance, and computed tomography imaging. The diagnostic algorithm also took into consideration peripheral blood and bone marrow biopsies analysis, trephine bone marrow biopsy assessment, and molecular testing for the $B C R-A B L$ fusion gene, as well as JAK2, CALR, and MPL mutation screening. 
Table 1

Detailed characteristics of the studied patients with ET $(n=162)$

\begin{tabular}{|ll|}
\hline Parameter & Value \\
\hline Patients, $\mathrm{n}(\%)$ & 162 \\
Male/females & $61 / 101(38 \% / 62 \%)$ \\
\hline Median age, years (range) & $62(22-95)$ \\
\hline JAK2V617F mutation-positive cases, $\mathrm{n}(\%)$ & $96(59.2 \%)$ \\
\hline CALR exon 9 mutation-positive cases, $\mathrm{n}(\%)$ & $31(19.1 \%)$ \\
\hline MPL exon 10 mutation-positive cases, $\mathrm{n}(\%)$ & $2(1.2 \%)$ \\
\hline Triple-negative cases, $\mathrm{n}(\%)$ & $29(17.9 \%)$ \\
\hline JAK2V617F $+C A L R+, \mathrm{n}(\%)$ & $3(1.9 \%)$ \\
\hline JAK2V617F $+M P L+, \mathrm{n}(\%)$ & $1(0.6 \%)$ \\
\hline Haemoglobin, $\mathrm{g} / \mathrm{dl}($ range) & $13.6(7.1-18.7)$ \\
\hline Platelet count, $\times 10^{9} / \mathrm{l}($ range) & $739(44-3424)$ \\
\hline White blood cells count, $\times 10^{9} / \mathrm{I}($ range) & $9.1(2.2-52.3)$ \\
\hline
\end{tabular}

The criteria for the diagnosis of post-ET-MF included the documentation of a previous diagnosis of ET, as defined by the WHO criteria, as well as the confirmation of bone marrow fibrosis grades $2-3$ (on $0-3$ scale), and at least two of the following criteria: anemia and $a \geq 2 \mathrm{~g} / \mathrm{dL}$ decrease from baseline hemoglobin level, a leucoerythroblastic peripheral blood picture, increasing splenomegaly, defined as either an increase in palpable splenomegaly of $\geq 5 \mathrm{~cm}$ (the distance of the tip of the spleen from the left costal margin) or the appearance of newly palpable splenomegaly, increased lactic dehydrogenase activity above the reference level, the development of $\geq 1$ of three constitutional symptoms: $>10 \%$ weight loss in 6 months, night sweats or unexplained fever $\left(>37.5^{\circ} \mathrm{C}\right)(34)$. The grade of the bone marrow fibrosis was assessed according to the European consensus on grading bone marrow fibrosis and the assessment of cellularity (35).

Methods

DNA and RNA were extracted from whole-blood leukocytes at the time of the initial evaluation due to the clinical suspicion of ET or disease evolution to the fibrotic phase. Genomic DNA was isolated using the QIAamp ${ }^{\circledR}$ DNA Blood Mini Kit (QUIAGEN). Total RNA was extracted with TRIzol ${ }^{\text {TM }}$ (Invitrogen). Purity and quantity of DNA and RNA was assessed with NanoDrop 1000 Spectrophotometer (Thermo Fisher Scientific). 
The assessment for the presence of the JAK2V617F mutation was conducted by a quantitative allelespecific PCR (ASO-PCR) according to Larsen et al. (36), and standardized in cooperation with MPN\&MPNr EuroNet (37). A high resolution melting analysis (HRMA) was used to detect mutations in CALR (exon 9), MPL (exon 10), SRSF2 (exon 1), and U2AF1 (exon 1 and 2) genes, as previously described by Klampfl et al. (12), Boyd et al. (38), Lin et al. (39) and Qian et al. (40), respectively. For the identification of the mutation type identified by HRMA, the Sanger sequencing was applied using the BigDye Terminator v3.1 Cycle Sequencing kit (Applied Biosystems, Thermo Fisher Scientific). The sequence of exon 13 (range Ile575 to Ala735) of the $A S X L 1$ gene (a region covering at least $83 \%$ of all known $A S X L 1$ mutations), was analyzed by Sanger sequencing $(41,42)$. To determine the JAK2 haplotype ${ }^{\text {GGCC_46/1 }}$, the rs 12343867 SNP was genotyped (43).

The analysis of the JAK2WT and JAK2V617F mRNA level, and PD-L1 mRNA level was done with the help of methods presented in the Supplementary file Methods. The gene copy number analysis (CNA) was performed with the use of the in-house developed Multiplex Ligation-dependent Probe Amplification (MLPA) test (Supplementary File Methods), designed and executed according to the well-established protocol, described before (44)(45).

\section{Statistical analysis}

All basic statistical analyses were performed in Statistica 13 [TIBCO Software Inc. (2017). Statistica (data analysis software system), version 13, www.statsoft.pl/statistica-i-tibco-software/. Depending on the distribution of the variables, a proper parametric (ANOVA F) or non-parametric (Mann-Whitney, KruskalWallis) test was used. In the case of variance and correlation study, an analysis was performed in $\mathrm{R}$ ver. 4.0.4 and R Studio ver. 1.4.1106, with the following R packages: base, ggcorrplot, dplyr, Hmisc. For the association of gene expression with the mutation status and clinical features, ANOVA and MANOVA tests were applied, for univariate and multivariate analysis of variance, respectively. Because the data did not follow a normal distribution, Spearman's rank correlation coefficients were calculated to estimate the correlation between the studied gene expression levels and blood parameters. Information on proteinprotein interactions and the co-expression score, based on the RNA expression pattern, was obtained from the STRING database v. 11.5 (https://string-db.org).

\section{Results}

\section{Study group characteristics}

A detailed characteristic of the studied ET pts $(n=162)$ is presented in Table 1. The comparison of the different molecularly defined subgroups showed that the hemoglobin blood concentration was significantly increased in the JAK2V617F-positive pts (ANOVA test, $\mathrm{p}=0.0165$; Supplementary File Results). On the contrary, there was no difference in the hemoglobin blood concentration between ET and post-ET-MF pts (Kruskal-Wallis test, $\mathrm{p}=0.0843$, Supplementary file Results). An analysis of the WBC count in relation to the JAK2V617F VAF ( $<50 \%$ and $\geq 50 \%)$ confirmed increased WBC count in pts with VAF 
$\geq 50 \%$ (Kruskal-Wallis test, $p=0.0018$, Supplementary file Results). The comparison of the platelet count in molecularly defined ET subgroups showed that the platelet count was significantly higher only in the CALR-mutation-positive vs. CALR-mutation-negative pts (Mann-Whitney test, $\mathrm{p}=0.0219$, Supplementary file Results). JAK2V617F mutation was present in 96 (59.3\%), CALR mutation in 31 (type 1-12, type 215 , others -4 , overall $19.1 \%$ ), and MPL mutations in two (1.2\%) out of the 162 pts. The co-occurrence of JAK2V617F and either CALR or MPL mutation was identified in three $(1.9 \%)$ and $1(0.6 \%)$ of the pts, respectively. Twenty-nine out of the $162(17.9 \%)$ analyzed pts were triple-negative. The ASXL 1, SRSF2, and U2AF1 mutations co-occurred in 7/96 (7.3\%) pts with JAK2V617F and 3/31 (9.7\%) pts with the CALR mutations. Thirteen non-driver mutations (ASXL1, SRSF2, U2AF1) were present in 11/162 (6.8\%) of the pts. The distribution of the non-driver gene mutations and molecular characteristics of ET and post-ET-MF pts harboring two or more mutations are shown in Supplementary file Results.

\section{ET and JAK2 haplotypeGGCC_46/1, driving mutations and JAK2 variant allele frequency}

The study of the JAK2 haplotype ${ }^{\text {GGCC_46/1 }}$ (tagged by the C allele of rs12343867 SNP) showed the C/C genotype in 31 (19\%), C/T in 73 (45\%), and T/T in 58 (36\%) pts. An analysis of the frequency of different

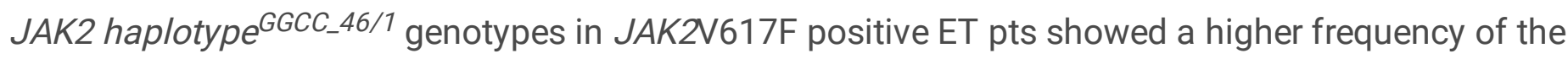
mutation in the $\mathrm{C} / \mathrm{C}$ vs. $\mathrm{C} / \mathrm{T}$ and $\mathrm{T} / \mathrm{T}$ haplotype carriers (Fisher exact test, $\mathrm{p}=0.0228$ ). No association of the JAK2 haplotype $\mathrm{GGCC}^{\mathrm{GC} / 1}$ was observed with the CALR mutations (data not shown). The JAK2V617F VAF distribution between different JAK2 haplotype ${ }^{G G C C_{-} 46 / 1}$ groups showed that the allelic burden was significantly higher in the $\mathrm{C} / \mathrm{C}$ than in other genotype carriers $[p=0.0198$, Supplementary file Results)]. Moreover, a significant increase of C/C genotype percentage was observed in the ET pts with JAK2V617F VAF $>50 \%$ [p = 0.0033; Supplementary file Results]. No distribution differences were noticed in terms of the WBC, platelet count, hemoglobin concentration, and age at diagnosis in different JAK2 haplotype ${ }^{\text {GGCC_46/1 }}$ groups.

\section{JAK2 gene copy number aberrations}

No copy-number alternations of the JAK2, and CD274 and PDCDL $1 G 2$ gene (encoding proteins PD-L1 and PD-L2, respectively) located in close proximity to JAK2 at the 9p24 chromosome locus was detected with the use of the in-house designed MLPA assay (Supplementary File Methods).

\section{JAK2V617F variant allele frequency and expression}

JAK2V617F VAF was determined by the ASO-PCR and MLPA technique $(r=0.9217)$. Low and high JAK2V617F allele burden was found in $81 / 96(84.4 \%)$ and $15 / 96(10.4 \%)$ of the pts, respectively. In the JAK2V617F positive ET pts, the JAK2V617F allelic mRNA level was positively correlated with the JAK2V617F VAF ( $r=0.6337$, Supplementary file Results). The analysis of the JAK2V617F mRNA showed the presence of a low-level JAK2V617F allele in four additional individuals in which the mutation was not detected by a DNA analysis with ASO-PCR and MLPA. The total JAK2 level in JAK2V617F positive pts was higher than in JAK2WT individuals ( $\mathrm{p}=0.0130$; Supplementary file Results). 
JAK2V617F VAF was higher in pts with leukocytosis at the time of evaluation $(\mathrm{p}=0.0015)$. In addition, the WBC count was higher in ET pts with high JAK2V617F VAF (Supplementary file Results). An analysis performed in pts with low ( $\leq 50 \%)$ and high (>50\%) JAK2V617F VAF did not show any differences in the mean values of hemoglobin concentration and platelet count in the blood. Pts carrying the CALR mutation had significantly higher median platelet count in comparison to the $C A L R$ mutation-negative pts (ANOVA test, $p=0.028$; Supplementary file Results). A similar analysis was not performed for the MPL mutated pts due to an insufficient number of positive pts $(n=3)$.

The total JAK2 level did not differ between the different genotypes of the JAK2 haplotype ${ }^{\mathrm{GGCC}} 46 \mathrm{6} / 1$. No male/female differences in the JAK2 level (both total, in all pts, and JAK2V617F positive pts) were observed.

PD-L 1 and JAK2 expression in the molecularly defined essential thrombocythaemia dependently from the bone marrow fibrosis grade

The total JAK2 expression level (JAK2V617F + wild type) showed no differences depending on the types of driving mutation (Kruskal-Wallis test, $p=0.1085$, Supplementary file Results). The expression of PD-L1 was significantly higher in the JAK2V617F mutation-positive vs. JAK2WT ET pts (Kruskal-Willis test, $\mathrm{p}=$ 0.0051) (Fig. 1). A similar analysis performed in the CALR mutation-positive and CALRWT pts showed no differences (Kruskal-Willis test, $\mathrm{p}=0.1908$; Fig. 1). There were no differences in the expression of PD-L1 in the JAK2/CALR/MPL mutation-positive and triple-negative ET pts. The PD-L1 expression in the JAK2V617F positive pts was higher than in the CALR mutation-positive and triple-negative pts (KruskalWillis test, $p=0.0439$ and $p=0.0485$, respectively, Fig. 1).

An analysis performed independently from the driver mutation status showed that the PD-L1 mRNA level was significantly lower in the post-ET-MF than ET pts (Kruskal-Willis test, $p=0.0176$, Fig. 1).

In addition, the total JAK2 level in post-ET-MF pts was lower than in ET pts without fibrotic transformation (Kruskal Willis test, $p=0.0003$ ). It was evident, despite the lack of differences between the JAK2V617F VAF in ET and post-ET-MF pts (Kruskal-Wallis test, $\mathrm{p}=0.3785$; Supplementary file Results). A detailed analysis has shown that the decrease in JAK2 and PD-L1 mRNA level was gradual, depending on the bone marrow fibrosis grade (MF grade 0 vs 1 vs $2 p<0.001$, respectively, Fig. 1). A weak correlation was observed in the case of the PD-L1 and JAK2 total (JAK2V617F + JAK2WT) mRNA level $(r=0.1259$, data not shown). Moreover, a low correlation between the PD-L1 mRNA level and JAK2V617F mutation VAF or the JAK2V617F allele mRNA level was found ( $r=0.204 ; p=0.049$ and $r=0.232 ; p=0.024$, respectively). The correlation between the expression of PDL1 and JAK2 (both, mutated and WT allele) (Fig. 2B) observed here corresponds with the data retrieved from the STRING database v. 11.5 (https://stringdb.org) (46). According to STRING, the predicted JAK2 and PDL1 protein interaction is supported by the co-expression of the genes encoding both proteins (Fig. 2A, RNA co-expression score 0.097).

The study of the relationship between the $P D-L 1$ expression and $46 / 1$ haplotype genotype, hemoglobin concentration, hematocrit value, leukocyte, and platelet count showed no differences (data not shown). 


\section{Discussion}

In 2008, Pardanani et al., based on an analysis of SNPs in four candidate genes (EPOR, MPL, GCSFR, $J A K 2)$, confirmed a significant association between the specific SNPs in the JAK2 gene (46/1 haplotype or GGCC haplotype) and the onset of sporadic MPNs (47). The term JAK2 haplotype ${ }^{\text {GGCC_46/1 }}$ refers to the combination of particular alleles of four SNPs inherited together and generating a GGCC allele's combination (rs3780367 T/G in intron 10, rs $10974944 \mathrm{C} / \mathrm{G}$ intron 12, rs $12343867 \mathrm{~T} / \mathrm{C}$ intron 14, and rs $1159782 \mathrm{~T} / \mathrm{C}$ intron 15). All four SNPs spanning the region of about $250 \mathrm{~kb}$ from JAK2 intron 10 to the INSL 4 gene, are in complete linkage disequilibrium (48). Now, the presence of $46 / 1$ haplotype is considered a factor predisposing to the JAK2V617F acquisition and MPN development (49-51). The allele frequency of the JAK2 haplotype ${ }^{G G C C}-46 / 1$ in the healthy population is about $24 \%$. Its presence is significantly increased (40 to $80 \%$ ) in JAK2V617F positive MPN pts (50-54). Recently, other germline variations of $H B S 1 L-M Y B, M E C O M$, and THRB-RARB have been also considered as factors determining the genetic predisposition to MPN $(55,56)$.

In our study, the distribution of different genotypes of the JAK2 haplotype ${ }^{\text {GGCC_46/1 }}$ in ET pts was similar to the previously published data (43). However, we showed that the JAK2 haplotype ${ }^{\text {GGCC_46/1 }}$ was significantly more frequent in JAK2V617F-positive than in CALR-positive ET pts. The latter observation is in agreement with the data previously reported by others (57).

The results of the study of an association between the presence of the JAK2 haplotype ${ }^{\mathrm{GGCC} \_46 / 1}$ and the predisposition to $C A L R$ positive or MPL positive MPN are still inconclusive. Also, the association between the JAK2 haplotype ${ }^{\mathrm{GGCC}} 46 / 1$ and triple-negative MPN occurrence is not fully determined (58).

Our results confirmed a significantly higher JAK2V617F VAF in homozygous carriers of JAK2 haplotype $\mathrm{GGCC}_{-46 / 1}$ (C/C genotype) and a significant increase of the $\mathrm{C} / \mathrm{C}$ genotype in ET pts with JAK2V617F VAF > 50\%.

An analysis of the total expression of the JAK2 gene in our ET pts group led to interesting results. The total JAK2 mRNA level did not significantly differ between pts defined by JAK2 haplotype ${ }^{\text {GGCC_46/1 }}$, but it was significantly increased in JAK2V617F positive pts. The association was evident, despite the confirmed correlation between the JAK2V617F VAF and JAK2V617F mRNA level. In our opinion, the increased total JAK2 expression in ET pts may result from different factors, including the allelic expression imbalance of JAK2 V617F mutation, MPN associated chronic inflammation, the presence of other non-coding SNP affecting the JAK2 expression, or mutations of epigenetic genes regulators [DNMT3A, TET2, EZH2, ASXL1, and IDH1/2 (via effects on TET2-mediated methylation)].

In 2013, Kim et al. demonstrated the JAK2V617F allelic imbalance expression by comparing the VAF in the total RNA (CDNA) and genomic DNA. They showed an increase of mutant allele at the RNA level, especially in ET (3 fold increase) and polycythaemia vera (PV) (2 fold increase) pts. It should be mentioned that the latter phenomenon was not observed in PMF pts (1.1 fold increase) (59). Another 
possibility of an increased total JAK2 mRNA expression in ET pts is abnormal JAK-STAT signaling. The potential link between a chronic inflammation and the development of myeloproliferative neoplasm has been postulated by Hasselbalch in 2012 (60). Later, it was shown that MPN driver mutations, such as JAK2V617F and MPL, were responsible for continuous, increased signaling via the JAK2-STAT pathway and the promotion of cytokine production by malignant and non-malignant cells (61-64). Probably, the abnormal JAK-STAT signaling resulted also in an abnormal total JAK2 expression. The above-mentioned hypothesis may be supported by the data concerning another JAK2 co-expressed gene - programmed death-ligand 1 (PD-L 1). In 2019, Guru et al. showed that JAK2 V617F mutation was accompanied by an increased PD-L1 expression. An increased expression of $P D-L 1$ may be caused by excessive activation of STAT3/5 which are the regulators of PD-L1. It was also shown that in the case of JAK2V617F, the PD-L 1 expression was mainly mediated by STAT3 (65). The overexpression of PD-L1 may also be caused by the acquisition of 9q UPD, which was confirmed in $6-18 \%$ of cases with ET $(32,66)$.

Recently published data confirmed that the mRNA level of STAT3 was significantly higher in JAK2V617F positive pts with PV and ET. Moreover, the up-regulation of STAT3 and STAT5 was associated with JAK2V617F VAF (67). It should be noted that the PD-L1 mRNA level is not affected by the PD-L 1 or JAK2 gene copy number variations, which has been shown in our study.

It cannot be excluded that another gene, SNP, also affects the JAK2 expression in pts with JAK2V617F positive ET. Recently, Cardinale et al. postulated that the rs1887428 SNP located in the promoter region of the JAK2 gene might influence the JAK2 expression in another JAK2V617F associated disease inflammatory bowel disease. The study confirmed a very modest impact of the above-mentioned SNP on the JAK2 expression and downstream amplification effect through the expression of the pathway member STAT5B and epigenetic modification of the JAK2 locus (68).

In 2020, Jacquelin et al. confirmed the mutational cooperation between the JAK2V617F expression and the loss of DNA methyltransferase $3 \mathrm{~A}$ in hematopoietic cells due to monoallelic or biallelic mutations of the DNMT3A gene. The coexistence of the above-mentioned mutations resulted in an aberrant selfrenewal, inflammatory signaling, driven by increased accessibility at enhancer elements, and finally the progression of PV to the fibrotic phase (69). Another possibility includes the presence of other JAK2 gene mutations affecting the mRNA splicing machinery. mRNA investigations showed no splicing defects around exon 14, and a constant level of mRNA accumulation per JAK2 gene copy, regardless of the presence or absence of the exon 14 JAK2V617F mutation (48).

Another important question concerning the fluctuation of the total JAK2 mRNA level during a natural disease outcome and evolution into the fibrotic phase (post-ET-MF). The results of our study showed a lower total JAK2 mRNA level (JAK2V617F + wild type) in post-ET-MF, in comparison to ET pts. The detailed analysis has shown that the decrease in JAK2 and PD-L1 mRNA expression is gradual and depends on the bone marrow fibrosis grade. A similar analysis concerning JAK2V617F VAF in ET and post-ET-MF pts did not reveal significant differences. This is incompatible with the previous data confirming high JAK2V617F VAF in post-ET-MF pts (70). This discrepancy results likely from other criteria 
used previously for the diagnosis of PV, ET, and post-ET-MF, which might result in over diagnosis of ET, even instead of PV $(71,72)$. Such a possibility was confirmed by the Swedish National MPN Registry data, documenting the increased frequency of newly diagnosed ET and reduced frequency of newly diagnosed PV from 2008 to 2015 (73). The interpretation of the obtained data is difficult due to the fact that the fibrotic transformation in ET is rarely observed and occurs in $9-15 \%$ of pts during a long-term follow-up $(74,75)$. On the other hand, it should be noted that the clinical MPN manifestation is not only related to the type of the driver mutation, but also depends on the profile of other coexisting mutations modifying the disease phenotype. The frequency and VAF of specific coexisting mutation(s) differ between pts, contributing to a specific disease phenotype in individual cases $(1,11,76)$. Among others, the mutations involved in the DNA methylation (ASXL1, TET2, DNMT3A, IDH1, IDH2), histone modification (EZH2, ASXL1), and splicing (SF3B1, SRSF2, U2AF1, and ZRSR2), and mutations in the transcription factors genes (RUNX1, NFE2, PPM1D, and TP53) are most frequently found in ET pts $(77,78)$. An adverse prognostic relevance of some of them (SH2B3/LNK, SF3B1, U2AF1, TP53, IDH2, and EZH2) on overall, leukemia-free and myelofibrosis-free survival of ET pts was recently demonstrated $(76,79-81)$.

Furthermore, the ASXL 1 mutations (most frequently found in post-ET-MF pts) have been also identified as a genetic risk factor for the fibrotic transformation of ET (21). Similarly, the co-occurrence of variants/mutations of SRSF2 and U2AF1 increased the risk of myelofibrotic evolution in PV and ET pts, respectively (80). The results of our study confirmed the co-occurrence of ASXL1, SRSF2, U2AF1 mutations in the studied ET pts group. Their frequency was below $10 \%$ and was similar to that reported by others $(79,82)$. However, it should be mentioned that its frequency in our JAK2V617F positive cases was 2-times higher in post-ET-MF than in ET individuals.

According to the limited published results, the risk of fibrotic transformation in ET pts carrying MPL mutation is higher than in other driver mutation types (83). Another factor predisposing to fibrotic transformation which has been postulated by Rumi et al. is a copy-neutral loss of heterozygosity (CNLOH) of chromosome 1p34.2 and high MPL allele burden (84). Recently, Ferrer-Marín et al. showed that the rs2431697 TT genotype affected the expression of miR-146a, a brake in NF-kB signaling, as a risk factor for the fibrotic transformation of PV and ET (85). It cannot be ruled out that epigenetic regulators affect the PD-L1 expression, as well. It was documented that PD-L1 expression might be downregulated by the abundance of miR-513, miR- 570, miR-34a, and miR-200 (86)(87)(88).

The interpretation of the lowered PD-L1 and JAK2 mRNA expression levels detected in our study in ET patients transforming to the fibrotic phase is difficult. The bone marrow failure in the advanced ET phase is likely associated with bone marrow fibrosis, reduction of bone marrow cellularity, bone marrow myeloid metaplasia, and diversity in molecular characteristics of the emerging subclones. Wang et al. showed that MF spleens contained greater numbers of malignant primitive hematopoietic cells than peripheral blood, and the significant increase in total CD34 + cells counts in JAK2V617F negative vs. positive samples (89). The latter may result in a distinct pattern of expression of JAK2 and PD- L1 genes (90)(91) (92). The association between $P D-L 1$ expression and JAK2V617F mutation was recently documented by Hara et al. in a patient with a coexisting JAK2V617F-positive ET and lung carcinoma in whom pembrolizumab (a drug directly blocking the interaction between PD-1 and its ligands, PD-L1, and PD-L2) 
treatment resulted in simultaneous normalization of the platelet count and a decrease of JAK2V617F VAF (93).

Despite the progress in the last years in the treatment of ET, none of the available therapies can change the outcome of the disease (94). Up to date, none of the therapies improve overall survival and prevent leukemic or fibrotic transformation (95). For these reasons, there is a need to identify a new potential molecular mechanism affecting the drug resistance to improve the ET outcome. One of them is the PD1/PD-L1 axis. In 2018, Holmström et al. documented that PD-L1 specific T cell response was stronger in pts with ET and PV and weaker and rarer in pts with pre-PMF and PMF MPN (96).

The results of our study can explain, at least in part, the lack of efficacy (clinical or bone marrow pathologic response) of the pembrolizumab treatment in patients with advanced primary, post-ET-MF and post-PV myelofibrosis (97) and shed more light on the relationship between the types of driver mutations, the PD-L1 expression and the ET progression to the fibrotic phase.

\section{Declarations}

Funding: The study was funded by: Poznań University of Medical Sciences statutory founds No 2705 and National Science Centre grant 2016/22/A/NZ2/00184

Acknowledgments: We would like to thank Katarzyna Lewandowska for editing and proofreading the final version of the manuscript.

Competing of Interests: The authors declare no conflict of interest.

Ethics approval statement: This study was approved by the Ethics Committee of Poznan University of Medical Sciences (number 1056/16 and 181/18) and was conducted in accordance with the Declaration of Helsinki.

Informed Consent Statement: Informed consent was obtained from all the subjects involved in the study.

Data Availability Statement: All data generated or analyzed during this study are included in this published article and its supplementary information files.

Author contributions: Conception and design, K.L. and P.K; Methodology, K.L., P.K., M.G.; Acquisition of the clinical data, K.L., E.P., M.J., M.M., P.M.N., ; Investigation, K.L., Z.K., M.G., M.W., P.M.N.; Analysis and interpretation of the clinical and laboratory data, Z.K., M.G., M.W., E.P., P.M.N., K.L., P.K.; Statistical analysis, M.G., L.H.; Project administration, K.L.; Formal analysis, K.L.; Writing-original draft, K.L.; Writing-review \& editing; L.K., P.K., M.G, Z.K., L.H. All authors have read and agreed to the published version of the manuscript. 


\section{References}

1. Vainchenker W, Kralovics R. Genetic basis and molecular pathophysiology of classical myeloproliferative neoplasms. Vol. 129, Blood. American Society of Hematology; 2017. p. 667-79.

2. Grinfeld J, Nangalia J, Green AR. Molecular determinants of pathogenesis and clinical phenotype in myeloproliferative neoplasms. Haematologica. 2017;102(1):7-17.

3. Jang MA, Choi CW. Recent insights regarding the molecular basis of myeloproliferative neoplasms. Korean J Intern Med. 2020;35(1):1-11.

4. Levine RL, Wadleigh M, Cools J, Ebert BL, Wernig G, Huntly BJP, et al. Activating mutation in the tyrosine kinase JAK2 in polycythemia vera, essential thrombocythemia, and myeloid metaplasia with myelofibrosis. Cancer Cell [Internet]. 2005 [cited 2021 Aug 2];7(4):387-97. Available from: https://pubmed.ncbi.nlm.nih.gov/15837627/

5. Kralovics R, Passamonti F, Buser AS, Teo S-S, Tiedt R, Passweg JR, et al. A Gain-of-Function Mutation of JAK2 in Myeloproliferative Disorders. N Engl J Med [Internet]. 2005 Apr 28 [cited 2021 Aug 2];352(17):1779-90. Available from: https://pubmed.ncbi.nlm.nih.gov/15858187/

6. Baxter EJ, Scott LM, Campbell PJ, East C, Fourouclas N, Swanton S, et al. Acquired mutation of the tyrosine kinase JAK2 in human myeloproliferative disorders. Lancet [Internet]. 2005 Mar [cited 2021 Aug 2];365(9464):1054-61. Available from: https://pubmed.ncbi.nlm.nih.gov/15781101/

7. Pikman Y, Lee BH, Mercher T, McDowell E, Ebert BL, Gozo M, et al. MPLW515L is a novel somatic activating mutation in myelofibrosis with myeloid metaplasia. PLoS Med. 2006;3(7):1140-51.

8. Pardanani AD, Levine RL, Lasho T, Pikman Y, Mesa RA, Wadleigh M, et al. MPL515 mutations in myeloproliferative and other myeloid disorders: A study of 1182 patients. Blood. 2006 Nov;108(10):3472-6.

9. Defour JP, Chachoua I, Pecquet C, Constantinescu SN. Oncogenic activation of MPL/thrombopoietin receptor by 17 mutations at W515: Implications for myeloproliferative neoplasms. Vol. 30, Leukemia. Nature Publishing Group; 2016. p. 1214-6.

10. Staerk J, Lacout C, Sato T, Smith SO, Vainchenker W, Constantinescu SN. An amphipathic motif at the transmembrane-cytoplasmic junction prevents autonomous activation of the thrombopoietin receptor. Blood. 2006 Mar;107(5):1864-71.

11. Nangalia J, Massie CE, Baxter EJ, Nice FL, Gundem G, Wedge DC, et al. Somatic CALR Mutations in Myeloproliferative Neoplasms with Nonmutated JAK2. N Engl J Med [Internet]. 2013 Dec 19 [cited 2021 Aug 2];369(25):2391-405. Available from: https://pubmed.ncbi.nlm.nih.gov/24325359/

12. Klampfl T, Gisslinger H, Harutyunyan AS, Nivarthi H, Rumi E, Milosevic JD, et al. Somatic Mutations of Calreticulin in Myeloproliferative Neoplasms. N Engl J Med [Internet]. 2013 Dec 19 [cited 2021 Aug 2];369(25):2379-90. Available from: https://pubmed.ncbi.nlm.nih.gov/24325356/ 
13. Pietra D, Rumi E, Ferretti V V., Di Buduo CA, Milanesi C, Cavalloni C, et al. Differential clinical effects of different mutation subtypes in CALR-mutant myeloproliferative neoplasms. Leukemia. 2016 Feb;30(2):431-8.

14. Cabagnols X, Defour JP, Ugo V, lanotto JC, Mossuz P, Mondet J, et al. Differential association of calreticulin type 1 and type 2 mutations with myelofibrosis and essential thrombocytemia: Relevance for disease evolution. Vol. 29, Leukemia. Nature Publishing Group; 2015. p. 249-52.

15. Di Buduo CA, Abbonante V, Marty C, Moccia F, Rumi E, Pietra D, et al. Defective interaction of mutant calreticulin and SOCE in megakaryocytes from patients with myeloproliferative neoplasms. Blood. 2020 Jan;135(2):133-44.

16. Masubuchi N, Araki M, Yang Y, Hayashi E, Imai M, Edahiro Y, et al. Mutant calreticulin interacts with MPL in the secretion pathway for activation on the cell surface. Leukemia. 2020 Feb;34(2):499-509.

17. Chachoua I, Pecquet C, El-Khoury M, Nivarthi H, Albu RI, Marty C, et al. Thrombopoietin receptor activation by myeloproliferative neoplasm associated calreticulin mutants. Blood [Internet]. 2016 Mar 10 [cited 2021 Aug 2];127(10):1325-35. Available from:

https://pubmed.ncbi.nlm.nih.gov/26668133/

18. Lussana F, Rambaldi A. Inflammation and myeloproliferative neoplasms. Vol. 85, Journal of Autoimmunity. Academic Press; 2017. p. 58-63.

19. Bock O, Höftmann J, Theophile K, Hussein K, Wiese B, Schlué J, et al. Bone morphogenetic proteins are overexpressed in the bone marrow of primary myelofibrosis and are apparently induced by fibrogenic cytokines. Am J Pathol. 2008;172(4):951-60.

20. Lu M, Xia L, Liu YC, Hochman T, Bizzari L, Aruch D, et al. Lipocalin produced by myelofibrosis cells affects the fate of both hematopoietic and marrow microenvironmental cells. Blood. 2015 Aug;126(8):972-82.

21. Cerquozzi S, Tefferi A. Blast transformation and fibrotic progression in polycythemia vera and essential thrombocythemia: A literature review of incidence and risk factors. Vol. 5, Blood Cancer Journal. Nature Publishing Group; 2015.

22. Passamonti F, Rumi E, Arcaini L, Boveri E, Elena C, Pietra D, et al. Prognostic factors for thrombosis, myelofibrosis, and leukemia in essential thrombocythemia: A study of 605 patients. Haematologica. 2008 Nov;93(11):1645-51.

23. Barbui T, Thiele J, Passamonti F, Rumi E, Boveri E, Ruggeri M, et al. Survival and disease progression in essential thrombocythemia are significantly influenced by accurate morphologic diagnosis: $\mathrm{A}$ international study. J Clin Oncol. 2011 Aug;29(23):3179-84.

24. Passamonti F, Rumi E, Pietra D, Elena C, Boveri E, Arcaini L, et al. A prospective study of 338 patients with polycythemia vera: The impact of JAK2 (V617F) allele burden and leukocytosis on fibrotic or leukemic disease transformation and vascular complications. Leukemia. 2010;24(9):1574-9.

25. Barbui T, Thiele J, Ferrari A, Vannucchi AM, Tefferi A. The new WHO classification for essential thrombocythemia calls for revision of available evidences. Vol. 10, Blood Cancer Journal. Springer Nature; 2020. 
26. Latagliata R, Polverelli N, Tieghi A, Palumbo GA, Breccia M, Sabattini E, et al. Comparison of JAK2V617F-positive essential thrombocythaemia and early primary myelofibrosis: The impact of mutation burden and histology. Hematol Oncol [Internet]. 2018 Feb 1 [cited 2021 Sep 18];36(1):26975. Available from: https://pubmed.ncbi.nlm.nih.gov/28509339/

27. Hao Y, Chapuy B, Monti S, Sun HH, Rodig SJ, Shipp MA. Selective JAK2 inhibition specifically decreases Hodgkin lymphoma and Mediastinal large B-cell lymphoma growth in vitro and in vivo. Clin Cancer Res. 2014 May;20(10):2674-83.

28. Barrett MT, Anderson KS, Lenkiewicz E, Andreozzi M, Cunliffe HE, Klassen CL, et al. Genomic amplification of 9p24.1 targeting JAK2, PD-L1, and PD-L2 is enriched in high-risk triple negative breast cancer. Oncotarget. 2015;6(28):26483-93.

29. Prestipino A, Emhardt AJ, Aumann K, O'Sullivan D, Gorantla SP, Duquesne S, et al. Oncogenic JAK2 V617F causes PD-L1 expression, mediating immune escape in myeloproliferative neoplasms. Sci Transl Med [Internet]. 2018 Feb 21 [cited 2021 Aug 11];10(429). Available from: https://pubmed.ncbi.nlm.nih.gov/29467301/

30. Tsushima F, Yao S, Shin T, Flies A, Flies S, Xu H, et al. Interaction between B7-H1 and PD-1 determines initiation and reversal of T-cell anergy. Blood [Internet]. 2007 Jul 1 [cited 2021 Aug 11];110(1):180-5. Available from: https://pubmed.ncbi.nlm.nih.gov/17289811/

31. Latchman Y, Wood CR, Chernova T, Chaudhary D, Borde M, Chernova I, et al. PD-L2 is a second ligand for PD-1 and inhibits T cell activation. Nat Immunol [Internet]. 2001 Mar [cited 2021 Aug 11];2(3):261-8. Available from: https://pubmed.ncbi.nlm.nih.gov/11224527/

32. Feenstra JDM, Jäger | Roland, Schischlik | Fiorella, Ivanov D, Eisenwort | Gregor, Rumi E, et al. PD-L1 overexpression correlates with JAK2-V617F mutational burden and is associated with 9p uniparental disomy in myeloproliferative neoplasms. Am J Hematol [Internet]. 2022 Jan 21 [cited 2022 Jan 22]; Available from: https://onlinelibrary.wiley.com/doi/full/10.1002/ajh.26461

33. Arber DA, Orazi A, Hasserjian R, Thiele J, Borowitz MJ, Le Beau MM, et al. The 2016 revision to the World Health Organization classification of myeloid neoplasms and acute leukemia. Vol. 127, Blood. American Society of Hematology; 2016. p. 2391-405.

34. Passamonti F, Mora B, Barraco D, Maffioli M. Post-ET and Post-PV Myelofibrosis: Updates on a Distinct Prognosis from Primary Myelofibrosis. Vol. 13, Current Hematologic Malignancy Reports. Current Science Inc.; 2018. p. 173-82.

35. Thiele J, Kvasnicka HM, Facchetti F, Franco V, Van Der Walt J, Orazi A. European consensus on grading bone marrow fibrosis and assessment of cellularity. Haematologica. 2005 Aug;90(8):112832.

36. Larsen TS, Christensen JH, Hasselbalch HC, Pallisgaard N. The JAK2 V617F mutation involves Band T-lymphocyte lineages in a subgroup of patients with Philadelphia-chromosome negative chronic myeloproliferative disorders. Br J Haematol. 2007 Mar;136(5):745-51.

37. Jovanovic J V., Ivey A, Vannucchi AM, Lippert E, Oppliger Leibundgut E, Cassinat B, et al. Establishing optimal quantitative-polymerase chain reaction assays for routine diagnosis and tracking of minimal 
residual disease in JAK2-V617F-associated myeloproliferative neoplasms: A joint European LeukemiaNet/MPN\&MPNr-EuroNet (COST action BM0902) stu. Leukemia. 2013 Oct;27(10):2032-9.

38. Boyd EM, Bench AJ, Goday-Fernández A, Anand S, Vaghela KJ, Beer P, et al. Clinical utility of routine MPL exon 10 analysis in the diagnosis of essential thrombocythaemia and primary myelofibrosis: Research paper. Br J Haematol. 2010 Apr;149(2):250-7.

39. Lin J, Yang J, Wen XM, Yang L, Deng ZQ, Qian Z, et al. Detection of SRSF2-P95 mutation by highresolution melting curve analysis and its effect on prognosis in myelodysplastic syndrome. PLoS One. 2014 Dec;9(12).

40. Qian J, Yao D ming, Lin J, Qian W, Wang C zhu, Chai H yan, et al. U2AF1 Mutations in Chinese Patients with Acute Myeloid Leukemia and Myelodysplastic Syndrome. Navarro A, editor. PLoS One. 2012 Sep;7(9):e45760.

41. Pratcorona M, Abbas S, Sanders MA, Koenders JE, Kavelaars FG, Erpelinck-Verschueren CAJ, et al. Acquired mutations in ASXL1 in acute myeloid leukemia: Prevalence and prognostic value. Haematologica. 2012 Mar;97(3):388-92.

42. Gelsi-Boyer V, Trouplin V, Adélaïde J, Bonansea J, Cervera N, Carbuccia N, et al. Mutations of polycomb-associated gene ASXL1 in myelodysplastic syndromes and chronic myelomonocytic leukaemia. Br J Haematol. 2009 Jun;145(6):788-800.

43. Pardanani A, Lasho TL, Finke CM, Gangat N, Wolanskyj AP, Hanson CA, et al. The JAK2 46/1 haplotype confers susceptibility to essential thrombocythemia regardless of JAK2V617F mutational statusclinical correlates in a study of 226 consecutive patients. Leukemia. 2010;24(1):110-4.

44. Kozlowski P, Roberts P, Dabora S, Franz D, Bissler J, Northrup H, et al. Identification of 54 large deletions/duplications in TSC1 and TSC2 using MLPA, and genotype-phenotype correlations. Hum Genet [Internet]. 2007 May [cited 2021 Sep 25];121(3-4):389-400. Available from: https://pubmed.ncbi.nlm.nih.gov/17287951/

45. Marcinkowska M, Wong KK, Kwiatkowski DJ, Kozlowski P. Design and generation of MLPA probe sets for combined copy number and small-mutation analysis of human genes: EGFR as an example. Vol. 10, TheScientificWorldJournal. Hindawi Limited; 2010. p. 2003-18.

46. Szklarczyk D, Gable AL, Lyon D, Junge A, Wyder S, Huerta-Cepas J, et al. STRING v11: Protein-protein association networks with increased coverage, supporting functional discovery in genome-wide experimental datasets. Nucleic Acids Res [Internet]. 2019 Jan 8 [cited 2021 Nov 28];47(D1):D607-13. Available from: https://pubmed.ncbi.nlm.nih.gov/30476243/

47. Pardanani A, Fridley BL, Lasho TL, Gilliland DG, Tefferi A. Host genetic variation contributes to phenotypic diversity in myeloproliferative disorders. Blood. 2008 Mar;111(5):2785-9.

48. Nauroy P, Delhommeau F, Baklouti F. JAK2V617F mRNA metabolism in myeloproliferative neoplasm cell lines. Vol. 4, Blood Cancer Journal. Nature Publishing Group; 2014. p. e222.

49. Kilpivaara O, Mukherjee S, Schram AM, Wadleigh M, Mullally A, Ebert BL, et al. A germline JAK2 SNP is associated with predisposition to the development of JAK2V617F-positive myeloproliferative neoplasms. Nat Genet. 2009 Apr;41(4):455-9. 
50. Olcaydu D, Harutyunyan A, Jäger R, Berg T, Gisslinger B, Pabinger I, et al. A common JAK2 haplotype confers susceptibility to myeloproliferative neoplasms. Nat Genet. 2009 Apr;41(4):450-4.

51. Jones A V., Chase A, Silver RT, Oscier D, Zoi K, Wang YL, et al. JAK2 haplotype is a major risk factor for the development of myeloproliferative neoplasms. Nat Genet. 2009;41(4):446-9.

52. Tefferi A, Lasho TL, Patnaik MM, Finke CM, Hussein K, Hogan WJ, et al. JAK2 germline genetic variation affects disease susceptibility in primary myelofibrosis regardless of V617F mutational status: Nullizygosity for the JAK2 46/1 haplotype is associated with inferior survival. Leukemia. 2010 Oct;24(1):105-9.

53. Andrikovics H, Nahajevszky S, Koszarska M, Meggyesi N, Bors A, Halm G, et al. JAK2 46/1 haplotype analysis in myeloproliferative neoplasms and acute myeloid leukemia. Vol. 24, Leukemia. Nature Publishing Group; 2010. p. 1809-13.

54. Matsuguma $M$, Yujiri T, Yamamoto $K$, Kajimura $Y$, Tokunaga $Y$, Tanaka $M$, et al. TERT and JAK2 polymorphisms define genetic predisposition to myeloproliferative neoplasms in Japanese patients. Int J Hematol. 2019 Dec;110(6):690-8.

55. Chiang $Y H$, Chang $Y C$, Lin HC, Huang $L$, Cheng $C C$, Wang WT, et al. Germline variations at JAK2, TERT, HBS1L-MYB and MECOM and the risk of myeloproliferative neoplasms in Taiwanese population. Oncotarget. 2017;8(44):76204-13.

56. Trifa AP, Bănescu C, Bojan AS, Voina CM, Popa Ștefana, Vișan S, et al. MECOM, HBS1L-MYB, THRBRARB, JAK2, and TERT polymorphisms defining the genetic predisposition to myeloproliferative neoplasms: A study on 939 patients. Am J Hematol. 2018 Jan;93(1):100-6.

57. Gau JP, Chen CC, Chou YS, Liu CJ, Yu Y Bin, Hsiao LT, et al. No increase of JAK2 46/1 haplotype frequency in essential thrombocythemia with CALR mutations: Functional effect of the haplotype limited to allele with JAK2V617F mutation but not CALR mutation. Blood Cells, Mol Dis. 2015 Jun;55(1):36-9.

58. Anelli L, Zagaria A, Specchia G, Albano F. The JAK2 GGCC (46/1) haplotype in myeloproliferative neoplasms: Causal or random? Vol. 19, International Journal of Molecular Sciences. MDPI AG; 2018.

59. Kim HR, Choi HJ, Kim YK, Kim HJ, Shin JH, Suh SP, et al. Allelic Expression Imbalance of JAK2 V617F Mutation in BCR-ABL Negative Myeloproliferative Neoplasms. PLoS One. 2013 Jan;8(1).

60. Hasselbalch HC. Perspectives on chronic inflammation in essential thrombocythemia, polycythemia vera, and myelofibrosis: Is chronic inflammation a trigger and driver of clonal evolution and development of accelerated atherosclerosis and second cancer? Vol. 119, Blood. Blood; 2012. p. 3219-25.

61. Koschmieder S, Mughal TI, Hasselbalch HC, Barosi G, Valent P, Kiladjian JJ, et al. Myeloproliferative neoplasms and inflammation: Whether to target the malignant clone or the inflammatory process or both. Vol. 30, Leukemia. Nature Publishing Group; 2016. p. 1018-24.

62. Geyer HL, Kosiorek H, Dueck AC, Scherber R, Slot S, Zweegman S, et al. Associations between gender, disease features and symptom burden in patients with myeloproliferative neoplasms: An analysis by the MPN QOL international working group. Haematologica. 2017;102(1):85-93. 
63. Lubberich RK, Walenda T, Goecke TW, Strathmann K, Isfort S, Brümmendorf TH, et al. Serum of myeloproliferative neoplasms stimulates hematopoietic stem and progenitor cells. PLoS One. 2018 May;13(5).

64. Kleppe M, Kwak M, Koppikar P, Riester M, Keller M, Bastian L, et al. JAK-STAT pathway activation in malignant and nonmalignant cells contributes to MPN pathogenesis and therapeutic response. Cancer Discov. 2015;5(3):316-31.

65. Guru SA, Alpana MP, Mir R, Najar IA, Zuberi M, Gupta N, et al. JAK2 (V617F) positively regulates PDL1 mRNA expression via STAT3/5 activation in MNP (PV and ET) patients. Ann Oncol. 2019 Oct;30:vi110.

66. Wang L, Wheeler DA, Prchal JT. Acquired uniparental disomy of chromosome $9 p$ in hematologic malignancies. Exp Hematol [Internet]. 2016 Aug 1 [cited 2022 Jan 23];44(8):644-52. Available from: https://pubmed.ncbi.nlm.nih.gov/26646991/

67. Guru SA, Sumi MP, Mir R, Waza AA, Bhat MA, Zuberi M, et al. Ectopic PD-L1 expression in JAK2 (V617F) myeloproliferative neoplasm patients is mediated via increased activation of STAT3 and STAT5. Hum Cell [Internet]. 2020 Oct 1 [cited 2021 Aug 14];33(4):1099-111. Available from: https://pubmed.ncbi.nlm.nih.gov/32430672/

68. Cardinale CJ, March ME, Lin X, Liu Y, Spruce LA, Bradfield JP, et al. Regulation of Janus Kinase 2 by an Inflammatory Bowel Disease Causal Non-coding Single Nucleotide Polymorphism. J Crohn's Colitis. 2020 Jun;14(5):646-53.

69. Jacquelin S, Straube J, Cooper L, Vu T, Song A, Bywater M, et al. Jak2V617F and Dnmt3a loss cooperate to induce myelofibrosis through activated enhancer-driven inflammation. Blood. 2018 Dec;132(26):2707-21.

70. Rumi E, Pietra D, Ferretti V, Klampfl T, Harutyunyan AS, Milosevic JD, et al. JAK2 or CALR mutation status defines subtypes of essential thrombocythemia with substantially different clinical course and outcomes. Blood. 2014 Mar;123(10):1544-51.

71. Tefferi A, Vardiman JW. Classification and diagnosis of myeloproliferative neoplasms: The 2008 World Health Organization criteria and point-of-care diagnostic algorithms. Vol. 22, Leukemia. Nature Publishing Group; 2008. p. 14-22.

72. Barbui T, Thiele J, Gisslinger H, Kvasnicka HM, Vannucchi AM, Guglielmelli P, et al. The 2016 WHO classification and diagnostic criteria for myeloproliferative neoplasms: document summary and indepth discussion. Vol. 8, Blood cancer journal. Blood Cancer J; 2018. p. 15.

73. Abdulkarim K, Samuelsson J, Johansson P, Andréasson B. Risk factors for vascular complications and treatment patterns at diagnosis of 2389 PV and ET patients: Real-world data from the Swedish MPN Registry. Eur J Haematol. 2017 Jun;98(6):577-83.

74. Tefferi A, Guglielmelli P, Larson DR, Finke C, Wassie EA, Pieri L, et al. Long-term survival and blast transformation in molecularly annotated essential thrombocythemia, polycythemia vera, and myelofibrosis. Blood. 2014 Oct;124(16):2507-13. 
75. Tefferi A. Primary myelofibrosis: 2021 update on diagnosis, risk-stratification and management. Am J Hematol. 2021 Jan;96(1):145-62.

76. Lundberg P, Karow A, Nienhold R, Looser R, Hao-Shen H, Nissen I, et al. Clonal evolution and clinical correlates of somatic mutations in myeloproliferative neoplasms. Blood. 2014 Apr;123(14):2220-8.

77. Leibundgut EO, Haubitz M, Burington B, Ottmann OG, Spitzer G, Odenike O, et al. Dynamics of mutations in patients with essential thrombocythemia treated with imetelstat. Haematologica. 2021 Jul;106(9):2397-404.

78. Loscocco GG, Guglielmelli P, Vannucchi AM. Impact of mutational profile on the management of myeloproliferative neoplasms: A short review of the emerging data. Onco Targets Ther. 2020 Dec;13:12367-82.

79. Tefferi A, Guglielmelli P, Lasho TL, Coltro G, Finke CM, Loscocco GG, et al. Mutation-enhanced international prognostic systems for essential thrombocythaemia and polycythaemia vera. $\mathrm{Br} \mathrm{J}$ Haematol. 2020 Apr;189(2):291-302.

80. Tefferi A, Lasho TL, Guglielmelli P, Finke CM, Rotunno G, Elala Y, et al. Targeted deep sequencing in polycythemia vera and essential thrombocythemia. Blood Adv. 2016 Nov;1(1):21-30.

81. Grinfeld J, Nangalia J, Baxter EJ, Wedge DC, Angelopoulos N, Cantrill R, et al. Classification and Personalized Prognosis in Myeloproliferative Neoplasms. N Engl J Med. 2018 Oct;379(15):1416-30.

82. Agarwal R, Blombery P, McBean M, Jones K, Fellowes A, Doig K, et al. Clinicopathological differences exist between CALR- and JAK2-mutated myeloproliferative neoplasms despite a similar molecular landscape: data from targeted next-generation sequencing in the diagnostic laboratory. Ann Hematol. 2017 May;96(5):725-32.

83. Elala YC, Lasho TL, Gangat N, Finke C, Barraco D, Haider M, et al. Calreticulin variant stratified driver mutational status and prognosis in essential thrombocythemia. Am J Hematol. 2016 May;91(5):503-6.

84. Rumi E, Pietra D, Guglielmelli P, Bordoni R, Casetti I, Milanesi C, et al. Acquired copy-neutral loss of heterozygosity of chromosome $1 p$ as a molecular event associated with marrow fibrosis in MPLmutated myeloproliferative neoplasms. Blood. 2013 May;121(21):4388-95.

85. Ferrer-Marín F, Arroyo AB, Bellosillo B, Cuenca EJ, Zamora L, Hernández-Rivas JM, et al. miR-146a rs2431697 identifies myeloproliferative neoplasm patients with higher secondary myelofibrosis progression risk. Leukemia. 2020 Oct;34(10):2648-59.

86. Chen XM. MicroRNA signatures in liver diseases. World J Gastroenterol [Internet]. 2009 Apr 14 [cited 2022 Jan 23];15(14):1665-72. Available from: https://pubmed.ncbi.nlm.nih.gov/19360909/

87. Chen L, Gibbons DL, Goswami S, Cortez MA, Ahn YH, Byers LA, et al. Metastasis is regulated via microRNA-200/ZEB1 axis control of tumour cell PD-L1 expression and intratumoral immunosuppression. Nat Commun [Internet]. 2014 Oct 28 [cited 2022 Jan 23];5. Available from: https://pubmed.ncbi.nlm.nih.gov/25348003/

88. Wang X, Li J, Dong K, Lin F, Long M, Ouyang Y, et al. Tumor suppressor miR-34a targets PD-L1 and functions as a potential immunotherapeutic target in acute myeloid leukemia. Cell Signal [Internet]. 
2015 Mar 1 [cited 2022 Jan 23];27(3):443-52. Available from:

https://pubmed.ncbi.nlm.nih.gov/25499621/

89. Wang X, Prakash S, Lu M, Tripodi J, Ye F, Najfeld V, et al. Spleens of myelofibrosis patients contain malignant hematopoietic stem cells. J Clin Invest [Internet]. 2012 Nov 1 [cited 2022 Jan 23];122(11):3888-99. Available from: http://www.jci.org

90. SHARMA M, BHAVANI C, SURESH SB, PAUL J, YADAV L, ROSS C, et al. Gene expression profiling of CD34(+) cells from patients with myeloproliferative neoplasms. Oncol Lett [Internet]. 2021 Mar 1 [cited 2022 Jan 23];21(3):1-1. Available from: http://www.spandidospublications.com/10.3892/ol.2021.12465/abstract

91. Mead AJ. Unravelling Heterogeneity of Stem and Progenitor Cells in Myeloid Neoplasms Through Single Cell Multi-omics. Blood. 2019 Nov 13;134(Supplement_1):SCI-31.

92. Kumar S, Sharawat SK. Epigenetic regulators of programmed death-ligand 1 expression in human cancers. Transl Res [Internet]. 2018 Dec 1 [cited 2022 Jan 23];202:129-45. Available from: https://pubmed.ncbi.nlm.nih.gov/30401465/

93. Hara R, Kawada H, Kikuti YY, Kikkawa E, Harada K, Aoyama Y, et al. A case of JAK2V617F-positive essential thrombocythemia where allele burden was reduced by a PD-1 inhibitor. Int J Hematol [Internet]. 2021 Apr 1 [cited 2021 Aug 11];113(4):606-10. Available from: https://pubmed.ncbi.nlm.nih.gov/33389657/

94. Gerds AT. Beyond JAK-STAT: Novel therapeutic targets in Ph-negative MPN. Hematol (United States) [Internet]. 2019 Dec 6 [cited 2021 Aug 11];2019(1):407-14. Available from: https://pubmed.ncbi.nlm.nih.gov/31808852/

95. Kishtagari A, Gerds AT. Unmet Need in Essential Thrombocythemia and Polycythemia Vera [Internet]. Vol. 35, Hematology/Oncology Clinics of North America. Hematol Oncol Clin North Am; 2021 [cited 2021 Aug 11]. p. 295-303. Available from: https://pubmed.ncbi.nlm.nih.gov/33641870/

96. Holmström MO, Riley CH, Skov V, Svane IM, Hasselbalch HC, Andersen MH. Spontaneous T-cell responses against the immune check point programmed-death-ligand 1 (PD-L1) in patients with chronic myeloproliferative neoplasms correlate with disease stage and clinical response. Oncoimmunology [Internet]. 2018 Jun 3 [cited 2021 Aug 11];7(6). Available from: https://pubmed.ncbi.nlm.nih.gov/29872567/

97. Hobbs G, Cimen Bozkus C, Moshier E, Dougherty M, Bar-Natan M, Sandy L, et al. PD-1 inhibition in advanced myeloproliferative neoplasms. Blood Adv. 2021 Dec 14;5(23):5086-97.

98. Gabert J, Beillard E, van der Velden VHJ, Bi W, Grimwade D, Pallisgaard N, et al. Standardization and quality control studies of "real time" quantitative reverse transcriptase polymerase chain reaction of fusion gene transcripts for residual disease detection in leukemia - A Europe Against Cancer Program [Internet]. Vol. 17, Leukemia. Nature Publishing Group; 2003 [cited 2021 Jun 3]. p. 2318-57. Available from: https://pubmed.ncbi.nlm.nih.gov/14562125/

99. Livak KJ, Schmittgen TD. Analysis of relative gene expression data using real-time quantitative PCR and the 2- $\Delta \Delta$ CT method. Methods [Internet]. 2001 [cited 2021 Aug 14];25(4):402-8. Available from: 
https://pubmed.ncbi.nlm.nih.gov/11846609/

100. Schouten JP, McElgunn CJ, Waaijer R, Zwijnenburg D, Diepvens F, Pals G. Relative quantification of 40 nucleic acid sequences by multiplex ligation-dependent probe amplification. Nucleic Acids Res. 2002 Jun;30(12):e57.

Figures
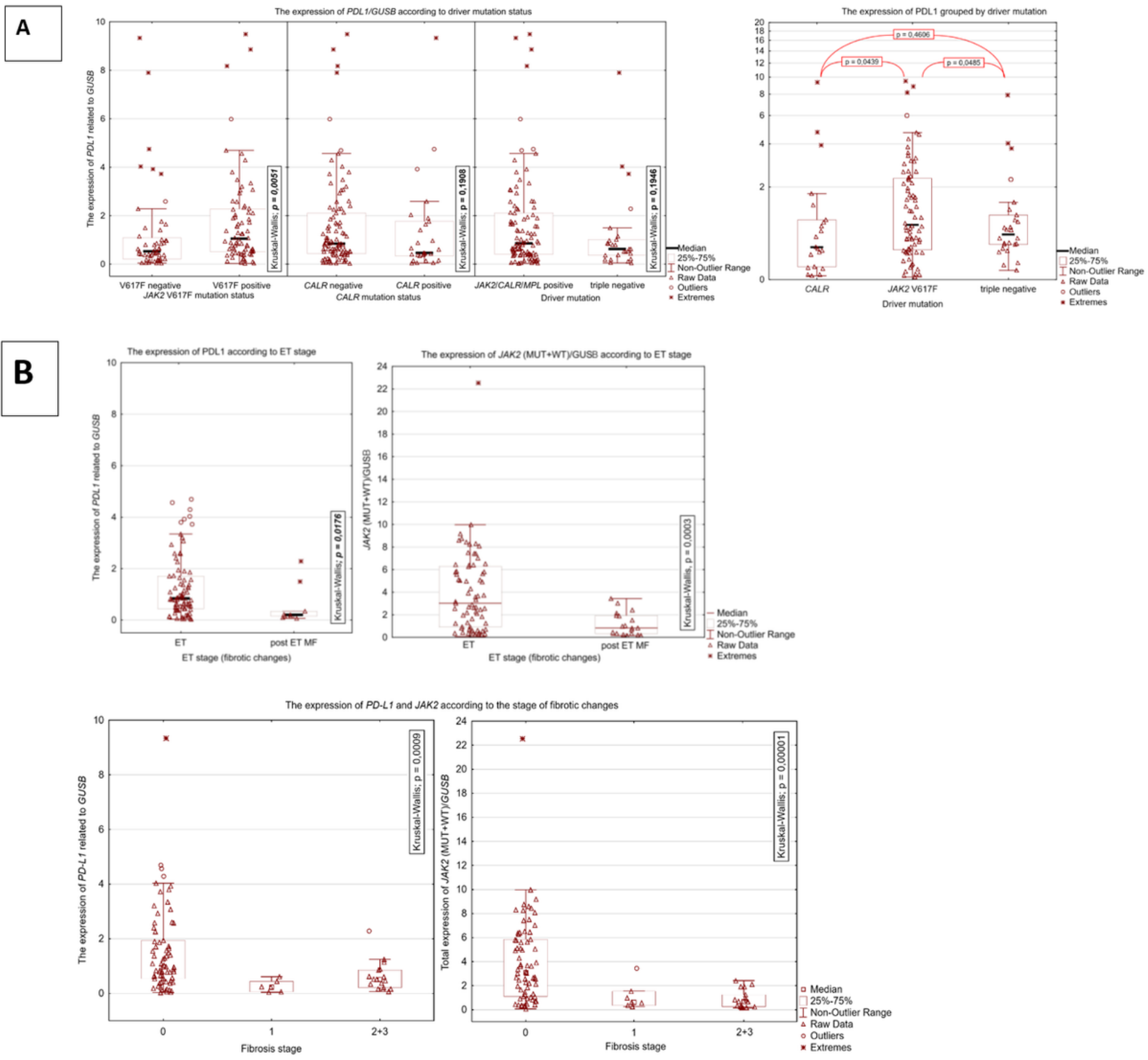

Figure 1 
The mRNA expression of programmed death ligand 1 (PD-L1) and Janus tyrosine kinase 2 [JAK2 $(\mathrm{WT}+\mathrm{V} 617 \mathrm{~F})]$, dependently from the ET driver mutation status $(\mathrm{A})$ and the grade of myelofibrosis (B)

A.

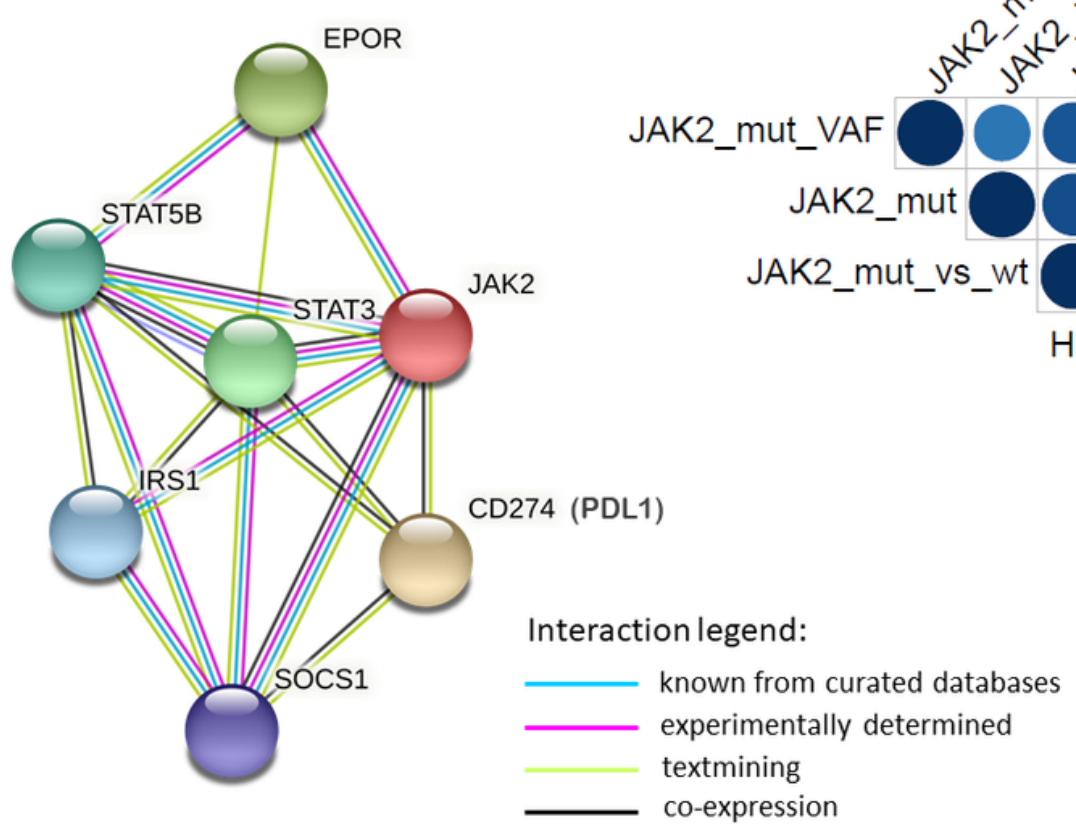

B.

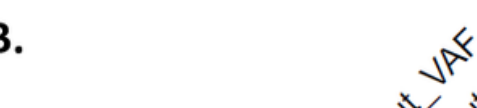

34<smiles>C[14CH2][14CH2][14CH2]</smiles><smiles></smiles>

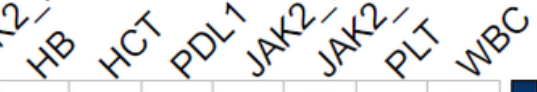

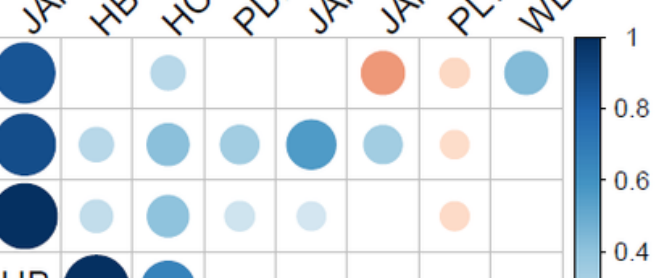
$\mathrm{HB}$
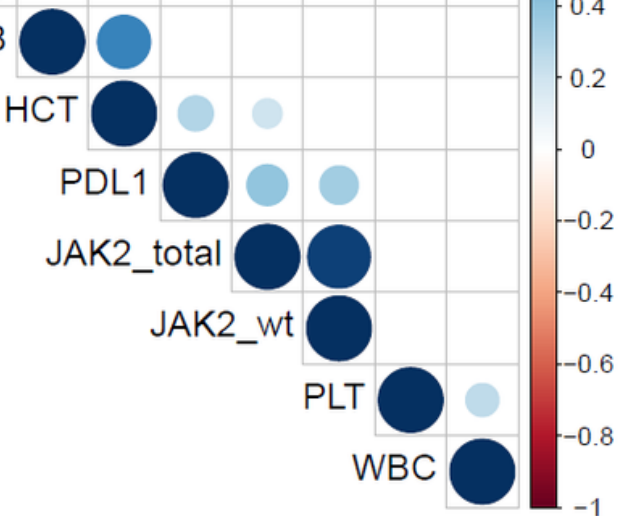

\section{Figure 2}

The association between the expression of $P D L 1$ and JAK2 [both, V617F mutated and wild type allele $(w t)]$ and complete blood count results in the studied cohort of ET patients. The color intensity and size of the squares are proportional to the correlation coefficients.

\section{Supplementary Files}

This is a list of supplementary files associated with this preprint. Click to download.

- SupplementaryFileMethods.docx

- SupplementaryfileResults.docx 